\title{
Level of physical activity, cardiorespiratory fitness and cardiovascular disease risk factors in a rural adult population in Sogn og Fjordane
}

\author{
Ane Kristiansen Solbraa ${ }^{1,2}$, Asgeir Mamen ${ }^{1}$, Geir Kåre Resaland ${ }^{1}$, Jostein Steene- \\ Johannessen ${ }^{1}$, Einar Ylvisåker ${ }^{1}$, Ingar Morten Holme ${ }^{2}$ and Sigmund Alfred Anderssen ${ }^{1,2}$ \\ 1) Sogn og Fjordane University College, Faculty of Teacher Education and Sport, Sogndal, Norway \\ 2) Norwegian School of Sport Sciences, Department of Sports Medicine, Oslo, Norway \\ Correspondence: Ane Kristiansen Solbraa, Sogn og Fjordane University College, Faculty of Teacher Education and Sport, \\ P.O. Box 133, 6851 Sogndal, Norway \\ E-mail: ane.solbraa@hisf.no Telephone:+4757676081 Telefax:+4757676051
}

\begin{abstract}
Background: Physical activity (PA) and high cardiorespiratory fitness (CRF) are associated with reduced risk of cardiovascular disease (CVD). Sogn og Fjordane County has the reputation of being the most healthy county in Norway. The level of PA and/or CRF may partly explain this health status. However, only one study with regional objectively measured PA data and one study with regional data on CRF currently exist. Thus, the aim of this study was to describe levels of PA, CRF and CVD risk factors in an adult population in the county of

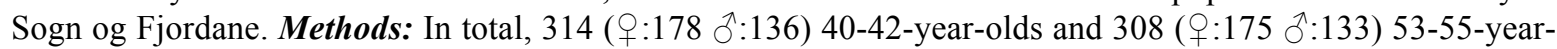
olds participated in this cross-sectional study. PA was measured objectively by accelerometry, while CRF was measured directly. Results: There were no sex differences in total PA level. For the 40-42-year-olds, women spent $6.0 \mathrm{~min} /$ day [95\% CI: -11.7 to -0.3 ] less participating in moderate PA compared to men. For the 53-55year-olds, women were inactive for $36.0 \mathrm{~min} /$ day [95\% CI: -55.2 to -16.8 ] less and they participated in light activity for $26.4 \mathrm{~min} /$ day [95\% CI: 7.7 to 45.2 ] more than men. In total, $30.0 \%$ [95\% CI: 24.8 to 35.2 ] of the 40-42-year-olds and 30.2\% [95\% CI: 25.0 to 35.4] of the 53-55-year-olds met the Norwegian recommendations for PA. CRF was $49.0 \mathrm{ml} \cdot \mathrm{kg}^{-1} \cdot \mathrm{min}^{-1}$ for men and $41.6 \mathrm{ml} \cdot \mathrm{kg}^{-1} \cdot \mathrm{min}^{-1}$ for women for the $40-42$-year-olds. For 53-55-year-olds CRF was $41.2 \mathrm{ml} \cdot \mathrm{kg}^{-1} \cdot \mathrm{min}^{-1}$ for men and $33.9 \mathrm{ml} \cdot \mathrm{kg}^{-1} \cdot \mathrm{min}^{-1}$ for women. Conclusions: These results suggest that the level of PA and CRF are higher compared to other available data. This might explain the advantageous health status in Sogn og Fjordane.
\end{abstract}

\section{BACKGROUND}

Regular physical activity (PA) is related to important aspects of health and PA is associated with increased longevity (1) and reduced risk of cardiovascular disease (CVD) and its risk factors (1-3). Physical inactivity is the fourth leading contributing factor to death globally (4). Furthermore, high cardiorespiratory fitness (CRF) is related to lower levels of CVD risk factors $(1,3)$ and CVD- and all-cause mortality $(1,5)$. Due to the health benefits achieved by regular PA, health-enhancing PA recommendations have been issued both internationally (6) and nationally $(7,8)$. Compliance with the PA recommendations has been associated with lower risk of death (9).

Monitoring PA levels is important for surveillance and assessment of the effectiveness of interventions or public health initiatives aimed at increasing PA (10). Assessments of PA have mainly been based upon selfadministered questionnaires (11-16). Norwegian PA data show conflicting results $(11,13,17,18)$. For instance, $68 \%$ of the Norwegians view themselves as physically active (19) and 33\% to $61 \%$ reports participation in PA at least twice a week (18). PA is multidi- mensional and these conflicting results might be partly due to methodological weaknesses and poor assessment methods. Self-reported instruments are widely used, but these have numerous limitations with respect to difficulties in ascertaining the frequency, duration and intensity of PA, capturing all domains of PA, social desirability bias, recall bias and reactivity $(10,12,20)$. Due to these limitations, objective assessment instruments, such as accelerometers, have been introduced to quantify PA $(10,21)$. These motion devices are able to determine pattern and intensity of PA (10) and have been used in large population-based studies $(13,22,23)$. In the Kan1 study, PA was assessed both by accelerometer and self-report in a representative population of Norwegian adults. Results showed that $18 \%$ of men and $22 \%$ of women met the objectively assessed PA recommendations. However, $43 \%$ of men and $32 \%$ of women met the recommendations when PA was measured by self-report (13). Similar findings are seen in Sweden and US were physical activity is measured both by self-report (24) and by accelerometry $(22,23$, 25 ) in large population samples.

Sogn og Fjordane County has Norway's longest living population. Life expectancy among men and 
women are respectively 78.2 and 83.5 years compared to a national average of 76.9 and 81.9 years (26). The county has a reputation of being the most healthy county in Norway (27) and is among the counties with lowest CVD mortality. In 2008 the county had 266 (men) and 153 (woman) deaths caused by CVD among every 100000 persons, compared to 275 (men) and 163 (woman) nationally (28). High levels of PA and/or CRF may partly explain this advantageous health status in Sogn og Fjordane. However, only one study with regional objectively measured PA data (13) and one study with regional data on CRF currently exist (29). Thus, the aim of this study was to describe levels of objectively measured PA, directly measured CRF and CVD risk factors in an adult population in the county of Sogn og Fjordane. Based on knowledge of the association between PA, CRF and CVD risk factors, we hypothesized that the population of Sogn og Fjordane County would be more physically active and have higher CRF compared to the rest of Norway.

\section{MeTHODS}

\section{Population}

All men and women in three geographically close municipalities in Sogn og Fjordane County (Luster, Sogndal and Leikanger) aged 40-42-years $(\mathrm{N}=553)$ and 53-55-years $(\mathrm{N}=543)$ at baseline were invited to participate in the study.

The study was divided into two phases. In phase 1, PA was measured objectively by accelerometry between October 2008 and December 2009. Invitation was sent via mail and as a reminder in the case of no response, the subjects were contacted by phone and/or mail. When an informed consent was received, a questionnaire and an accelerometer were sent to the subjects via mail and returned after use in a prepaid envelope. In total, 314 (61\%) 40-42-year-olds and 308 (62\%) 5355 -year-olds participated in phase 1 (figure 1).

All subjects from phase 1 holding valid data on both questionnaire and accelerometry were considered eligible subjects for phase 2. From a random sample, 200 subjects in both age-groups were invited to participate in phase 2. In total, 107 (56\%) 40-42-year-olds and 111 (62\%) 53-55-year-olds participated in phase 2 (figure 1). In phase 2, CRF and CVD risk factors were measured. The physical examination was performed between March 2010 and September 2010. Tests were performed at Sogn og Fjordane University College. The same experienced test personnel performed all examinations, except for measurements of blood pressure and blood sampling, which were carried out by two experienced nurses. The subjects signed an informed consent and a health status declaration prior to testing.

The study was approved by the Regional Committee for Medical Research Ethics, the Norwegian Social Science Data Services AS and the Norwegian Tax Department.

\section{Measures}

\section{Anthropometry}

Height and weight for all subjects were self-reported through a questionnaire in phase 1 . Furthermore, waist circumference was measured by anthropometric tape at midpoint between the lowest rib and crista iliaca after a normal expiration in phase 2 . The mean value of three measurements was used in statistical analyses.

\section{Blood pressure}

Systolic (SBP) and diastolic (DBP) blood pressure were measured automatically using an Omron HEM907 blood pressure monitor (Omron Healthcare, Inc, Vernon Hills, IL, US) for subjects attending phase 2. The subjects rested for five minutes and a cuff with appropriate size was placed on the left upper arm. Three repeated measures were taken at one-minute intervals. The mean value of the two last measurements was used in statistical analyses.

\section{Blood analysis}

Non-fasting intravenous blood-samples were taken from the antecubital vein for subjects attending phase 2. The samples were spun for 12 minutes at $3000 \mathrm{rpm}$ within 60 minutes. The blood-samples were sent by overnight express mail and analyzed by the Department of Medical Biochemistry at Oslo University Hospital, Ullevaal (Norway). Total cholesterol (TC), highdensity lipoprotein cholesterol (HDL-c), triglycerides (TG) and glucose were measured in serum using the Cobas Integra 800 analyzer from Roche (F. HoffmannLa Roche Ltd, Basle, Switzerland). Low-density lipoprotein (LDL-c) was estimated from TC, HDL-c and TG by the Friedewald formula (30). Blood samples are missing from one subject in the 40-42-year-old-group and three subjects in the 53-55-year-old-group due to technical problems.

\section{Cardiorespiratory fitness}

For subjects attending phase 2, a CRF (maximal oxygen uptake $\left(\mathrm{VO}_{2 \max }\right)$ ) test was performed on a Woodway PPS 55 treadmill (Woodway $\mathrm{GmbH}$, Weihlam Rhine, Germany) and oxygen uptake was measured with a Moxus metabolic analyzer (AEI Technologies, Inc. Naperville, IL, USA) with accompanying software (Max II). A modified Balke protocol was used (31). The protocol started with constant speed and progressing inclination $(2 \%)$ every minute for the first 12 minutes, then speed was increased with $0.5 \mathrm{~km} \cdot \mathrm{h}^{-1}$ each minute until voluntary exhaustion. Before testing, a Polar heart rate (HR) monitor (Polar OY, Kempele, Finland) was fitted to the chest by an elastic strap. The subjects then had two to seven minutes of adaption to the treadmill $\left(2.0-4.8 \mathrm{~km} \cdot \mathrm{h}^{-1}\right)$. To collect expired air a Hans Rudolph Vmask (Hans Rudolph Inc, Kansas City, MO, USA), was attached to a Hans Rudolph twoway non re-breathable valve (HR 2700), fitted onto the subject, controlled for air tightness and connected to the metabolic analyzer. Depending on health status, the subjects performed two different test protocols. 

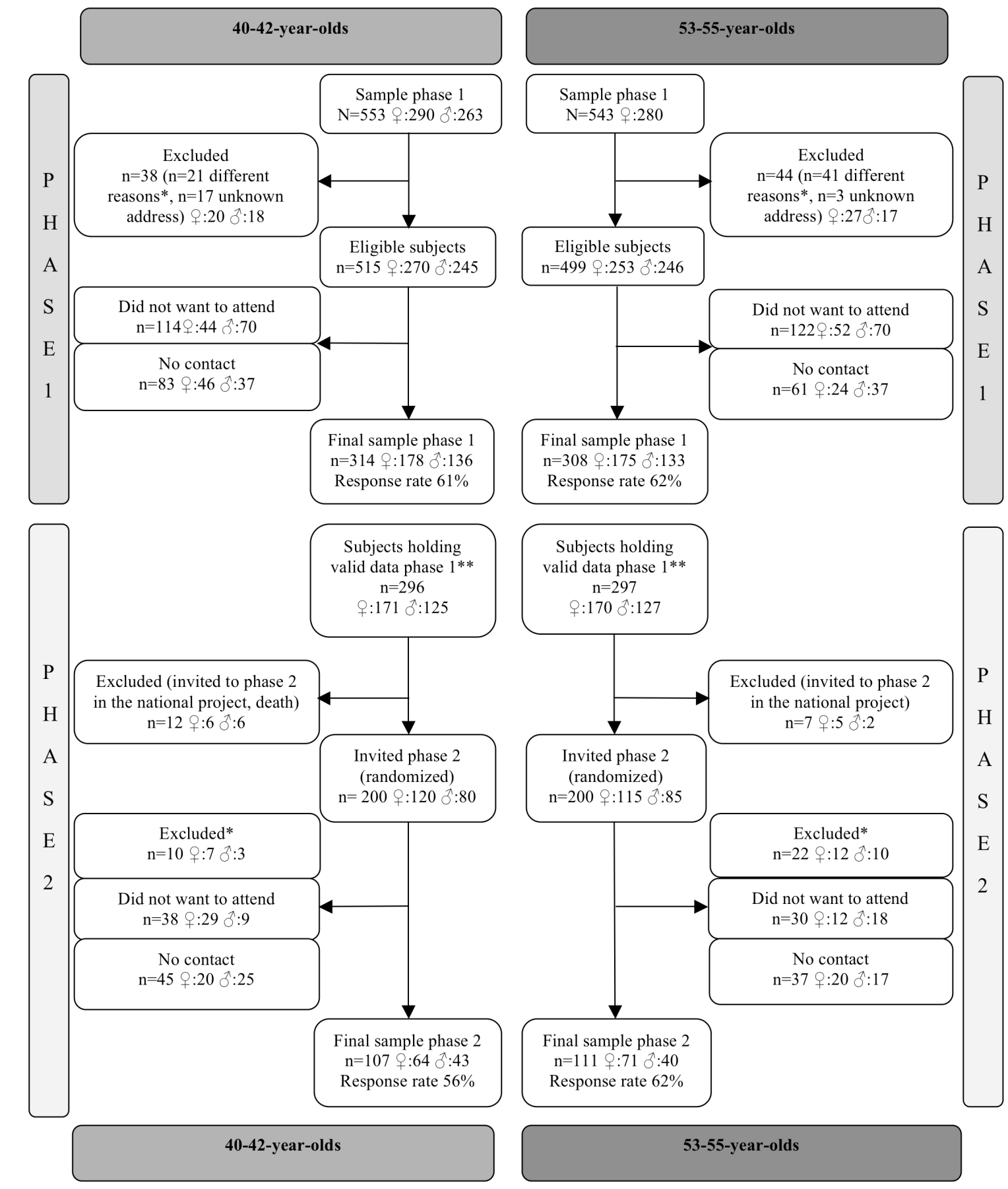

Figure 1. Overview of the study design and the subjects.

* Health situation, work situation, moved from the area

** Returned both valid accelerometer and valid questionnaire

Subjects with a low CVD risk (less than two healthrisk items from the health status declaration) started at $4.8 \mathrm{~km} \cdot \mathrm{h}^{-1}$, while subjects with a higher risk started at $3.8 \mathrm{~km} \cdot \mathrm{h}^{-1}$. Twelve subjects in the 53-55-year-oldgroup used the higher-risk protocol. The Borg rating of perceived exertion (RPE) was recorded at the end of the test. If Borg RPE was $\geq 17$ and/or RER (respiratory exchange ratio) was $\geq 1.10$, the test was accepted as maximal. In the 40-42-year-old-group, 82 subjects had accepted recordings from the $\mathrm{VO}_{2 \max }$ test. Ten subjects conducted the test, but did not meet the criteria for a maximal test; 14 subjects did not have valid data due to technical problems, while one subject did not perform the test due to poor health status. In the 53-55year-old-group 99 subjects had valid recordings from the $\mathrm{VO}_{2 \max }$ test. Nine subjects conducted the test, but did not meet the criteria for a maximal test, while three subjects did not test due to poor health status. $\mathrm{VO}_{2 \max }$ 
was adjusted by a correction factor of 1.059 for analyzer differences in the national Kan1-study by an Oxycon Pro System (13).

\section{Physical activity}

PA was measured with the ActiGraph GT1M accelerometer (ActiGraph, LLC, Pensocola, Florida, USA). The accelerometer was initialized and downloaded by the software program ActiLife (ActiGraph, Pensacola, Florida, USA). The subjects were instructed to wear the monitor above the right hip during all waking hours for seven consecutive days, except during water activities and showering. A SAS-based software (SAS-Institute Inc, Cary, North Carolina, USA) called CSA Analyser (csa.svenssonspork.dk) was used for the data reduction.

The epoch length was set at 10 seconds and later collapsed into 60-second epochs for comparisons with other studies. All night activity (between 00:00 and 06:00) and all sequences of at least 60 minutes of consecutive zero counts, with an allowance for one to two minutes of activity, were excluded from each individual's recording. Subjects with at least ten hours of PA data for at least four days were included in further analyses. A total of 300 40-42-year-olds and 298 53-55year-olds provided valid recordings. PA is presented as overall PA (mean counts per minute, cpm) in total and split by weekday and weekend, inactivity ( $\mathrm{min} /$ day), light activity (min/day), moderate PA (MPA, min/day), vigorous PA (VPA, min/day) and the combined moderate to vigorous PA (MVPA, min/day). The following cut-off points were used: $<100 \mathrm{cpm}$ for inactivity, 100$2019 \mathrm{cpm}$ for light activity, 2020-5998 cpm for MPA and $\geq 5999 \mathrm{cpm}$ for VPA (23). Adherence to PA recommendations was examined by determining the proportion of the subjects that met the current Norwegian PA recommendations. The current recommendations are to accumulate at least 30 minutes of daily moderate PA in bouts of at least 10 minutes (7). For analysis, interruptions of one or two minutes of activity counts below threshold in the sustained MVPA bout were allowed. This allows for small breaks in activity (e.g. a water break) and avoids the entire bout being deleted if a small drop in intensity occurs in a sustained bout of activity.

\section{Other measures}

A questionnaire was used to record smoking habits (self-reported) in three categories: smokes, does not smoke, smoked earlier. Level of education was recorded as one of the following categories: less than high school, high school, university $<4$ years and university $\geq 4$ years.

\section{Statistics}

All statistical analyses were performed using Statistical Package for the Social Sciences (SPSS) version 17.0 (SPSS Inc., Chicago, IL, USA). The distribution of each variable was tested for normality (ShaprioWilk). Results are presented as mean (SD) and mean difference [ $95 \%$ confidence interval], unless otherwise stated. General linear modelling was used to compare group means, and chi-square analyses were used to determine differences in distribution of education level and smoking habits between selected groups. A Pearson's correlation was used to investigate the relationship between PA and CRF. Significance level was set to $\mathrm{p} \leq 0.05$.

\section{RESUlts}

Table 1 shows anthropometric characteristics, educational level and smoking habits by age-groups in total and by sex. In the 40-42-year-old-group significant differences between the sexes were observed in all variables except for smoking. Women had a significantly longer education compared to men $(p<0.001)$. Furthermore, women had $1.5 \mathrm{~kg} / \mathrm{m}^{2}$ [95\% CI: -2.4 to $-0.6]$ lower BMI (body mass index) compared to men. Thirty-two percent of women and $47.2 \%$ of men were overweight (BMI 25.0-29.9) and 14.8\% of women and $13.0 \%$ of men were obese (BMI $\geq 30.0$ ). In the 53-55year-old-group, significant differences between the sexes were observed in all variables except for education level and smoking. Women had $1.9 \mathrm{~kg} / \mathrm{m}^{2}[95 \%$ CI: -2.8 to -1.0$]$ lower BMI compared to men. The percentage of overweight subjects was $35.0 \%$ for women and $50.4 \%$ for men, whereas $8.0 \%$ of women and $13.6 \%$ of men were obese. There was a significant interaction between age-group and sex for education level.

Table 2 shows levels of CVD risk factors by agegroup, in total and by sex. Well-known gender differences in HDL-c and waist circumference were observed, and also lower blood pressure in women as compared to men at age below 50 years is a consistent observation in the literature (32). In addition, significant differences were observed between the two agegroups showing that the 40-42-year-old-group had 8.2 $\mathrm{mmHg}$ [95\% CI: -11.9 to -4.5 ] lower SBP, $4.6 \mathrm{mmHg}$ [95\% CI: -7.0 to -2.1 ] lower DBP, $0.55 \mathrm{mmol} / \mathrm{L}$ [95\% CI: -0.80 to -0.29$]$ lower TC and $0.41 \mathrm{mmol} / \mathrm{L}[95 \%$ CI: -0.64 to -0.19$]$ lower LDL-c compared to the 53 55-year-old-group.

In total, the two age-groups had 6.9 (0.8) valid days of accelerometer measurements. The mean accelerometer wear time among subjects with at least 4 days of valid measures was 14.9 (0.9) hours per day. Table 3 shows PA level by age group, in total and by sex. In the 40-42-year-old-group few significant differences between the sexes were observed. Nevertheless, women spent $6.0 \mathrm{~min} /$ day [95\% CI: -11.7 to -0.3 ] less participating in MPA compared to men. In the 53-55-yearold-group, women were inactive for $36.0 \mathrm{~min} /$ day [ $95 \%$ CI: -55.2 to -16.8 ] less than men. In light activity, women spent $26.4 \mathrm{~min} /$ day [95\% CI: 7.7 to 45.2 ] more compared to men. In addition, a significant difference was observed between the age-groups in VPA. The 4042-year-old-group spent $2.7 \mathrm{~min} /$ day [95\% CI: 1.6 to 3.9] more participating in VPA compared to the 53-55year-old-group. Furthermore, for the test of interaction 
Table 1. Mean (SD) or $\mathrm{n}(\%)$ of anthropometric characteristics and educational level (phase 1) by age and sex.

\begin{tabular}{|c|c|c|c|c|c|c|c|c|c|c|}
\hline & \multicolumn{4}{|c|}{ 40-42-year-olds } & \multicolumn{4}{|c|}{ 53-55-year-olds } & \multirow[b]{2}{*}{$\begin{array}{l}\text { P for age- } \\
\text { group }\end{array}$} & \multirow[b]{2}{*}{$\begin{array}{l}\text { P for age- } \\
\text { group*sex }\end{array}$} \\
\hline & Men & Women & All & $P$ for sex & Men & Women & All & $P$ for sex & & \\
\hline Number (range) & $123-136$ & $169-178$ & $292-314$ & & $124-132$ & $163-175$ & $288-307$ & & & \\
\hline Age (yr) & $40.8(0.9)$ & $40.7(0.9)$ & $40.8(0.9)$ & 0.705 & $53.7(1.0)$ & $53.5(0.9)$ & $53.6(1.0)$ & 0.215 & & 0.504 \\
\hline Height (cm) & $181.0(7.3)$ & $168.5(5.6)$ & $173.8(8.9)$ & $<0.001$ & $180.0(6.7)$ & $166.9(5.5)$ & $172.5(8.9)$ & $<0.001$ & 0.070 & 0.558 \\
\hline Weight (kg) & $86.5(13.1)$ & $70.6(11.9)$ & $77.4(14.7)$ & $<0.001$ & $86.8(14.4)$ & $69.6(11.3)$ & $77.1(15.3)$ & $<0.001$ & 0.809 & 0.533 \\
\hline Education level, n (\%) & & & & $<0.001$ & & & & 0.919 & 0.001 & 0.002 \\
\hline University $\geq 4$ yrs & $23(17.7)$ & $66(37.7)$ & $89(29.2)$ & & $31(24.0)$ & $41(23.4)$ & $72(23.7)$ & & & \\
\hline University $<4$ yrs & $27(20.8)$ & $49(28.0)$ & $76(24.9)$ & & $27(20.9)$ & $35(20.0)$ & $62(20.4)$ & & & \\
\hline High school & $75(57.7)$ & $57(32.6)$ & $132(43.3)$ & & $52(40.3)$ & $79(45.1)$ & $131(43.1)$ & & & \\
\hline Less than high school & $5(3.8)$ & $3(1.7)$ & $8(2.6)$ & & $19(14.7)$ & $20(11.4)$ & $39(12.8)$ & & & \\
\hline Smoking, n (\%) & & & & 0.737 & & & & 0.443 & 0.378 & 0.340 \\
\hline Have never smoked & $76(58.9)$ & $107(60.5)$ & $183(59.8)$ & & $77(58.8)$ & $92(53.5)$ & $169(55.8)$ & & & \\
\hline Smoked earlier & $30(23.3)$ & $41(23.2)$ & $71(23.2)$ & & $31(23.7)$ & $47(27.3)$ & $78(25.7)$ & & & \\
\hline
\end{tabular}

BMI, body mass index

Table 2. Mean (SD) of cardiovascular disease risk factors (phase 2) by age and sex.

\begin{tabular}{|c|c|c|c|c|c|c|c|c|c|c|}
\hline & \multicolumn{4}{|c|}{ 40-42-year-olds } & \multicolumn{4}{|c|}{ 53-55-year-olds } & \multirow[b]{2}{*}{$\begin{array}{l}\text { P for age- } \\
\text { group }\end{array}$} & \multirow[b]{2}{*}{$\begin{array}{l}\text { P for age- } \\
\text { group*sex }\end{array}$} \\
\hline & Men & Women & All & $P$ for sex & Men & Women & All & $P$ for sex & & \\
\hline Number (range) & $43-44$ & $62-63$ & $105-107$ & & $37-40$ & $69-71$ & $106-111$ & & & \\
\hline SBP (mmHg) & $135.7(11.6)$ & $124.7(11.6)$ & $129.2(12.8)$ & $<0.001$ & $140.0(13.9)$ & $135.9(15.6)$ & $137.4(15.0)$ & 0.179 & $<0.001$ & 0.063 \\
\hline DBP (mmHg) & $80.8(9.2)$ & $76.7(9.4)$ & $78.3(9.5)$ & 0.029 & $84.5(8.7)$ & $82.0(9.0)$ & $82.9(9.0)$ & 0.151 & $<0.001$ & 0.544 \\
\hline $\mathrm{TC}(\mathrm{mmol} / \mathrm{L})$ & $5.45(0.98)$ & $5.17(0.90)$ & $5.29(0.94)$ & 0.142 & $5.68(0.99)$ & $5.91(0.93)$ & $5.83(0.95)$ & 0.224 & $<0.001$ & 0.058 \\
\hline HDL-c $(\mathrm{mmol} / \mathrm{L})$ & $1.42(0.38)$ & $1.70(0.43)$ & $1.58(0.43)$ & 0.001 & $1.33(0.38)$ & $1.82(0.52)$ & $1.64(0.53)$ & $<0.001$ & 0.386 & 0.093 \\
\hline $\mathrm{TG}(\mathrm{mmol} / \mathrm{L})$ & $1.67(1.01)$ & $1.01(0.50)$ & $1.28(0.82)$ & $<0.001$ & $1.99(1.46)$ & $1.27(0.57)$ & $1.53(1.04)$ & 0.006 & 0.055 & 0.819 \\
\hline LDL-c $(\mathrm{mmol} / \mathrm{L})$ & $3.29(0.74)$ & $3.01(0.84)$ & $3.12(0.81)$ & 0.090 & $3.58(0.87)$ & $3.52(0.83)$ & $3.54(0.84)$ & 0.729 & $<0.001$ & 0.365 \\
\hline Glucose $(\mathrm{mmol} / \mathrm{l})$ & $5.41(1.18)$ & $5.24(1.07)$ & $5.31(1.11)$ & 0.434 & $5.20(0.88)$ & $5.38(1.00)$ & $5.31(0.96)$ & 0.355 & 0.963 & 0.231 \\
\hline Waist $(\mathrm{cm})$ & $92.2(12.5)$ & $82.9(12.0)$ & $86.7(13.0)$ & $<0.001$ & $94.5(10.5)$ & $83.5(10.5)$ & $87.5(11.7)$ & $<0.001$ & 0.661 & 0.619 \\
\hline
\end{tabular}

SBP, systolic blood pressure; DBP, diastolic blood pressure; TC, total cholesterol; HDL-c, high density lipoprotein; LDL-c, low density lipoprotein; TG, triglyceride

Table 3. Mean (SD) of physical activity (phase 1) by age and sex.

\begin{tabular}{|c|c|c|c|c|c|c|c|c|c|c|}
\hline & \multicolumn{4}{|c|}{ 40-42-year-olds } & \multicolumn{4}{|c|}{ 53-55-year-olds } & \multirow[b]{2}{*}{$\begin{array}{l}\text { P for age- } \\
\text { group }\end{array}$} & \multirow[b]{2}{*}{$\begin{array}{l}\text { P for age- } \\
\text { group*sex }\end{array}$} \\
\hline & Men & Women & All & $P$ for sex & Men & Women & All & $P$ for sex & & \\
\hline Number (range) & $127-129$ & $168-171$ & $295-300$ & & $125-128$ & $169-170$ & $294-298$ & & & \\
\hline Overall PA (cpm) & $424.0(161.3)$ & $402.9(142.4)$ & 412.0 & 0.229 & $382.7(144.3)$ & $402.9(143.9)$ & $394.2(144.2)$ & 0.230 & 0.142 & 0.103 \\
\hline Inactivity (min/day) & $516.5(86.7)$ & $513.0(74.0)$ & $514.5(79.6)$ & 0.700 & $546.2(85.2)$ & $510.2(81.8)$ & $525.7(85.0)$ & $<0.001$ & 0.098 & 0.014 \\
\hline Light activity (min/day) & $340.9(77.5)$ & $336.4(75.2)$ & $338.3(76.1)$ & 0.610 & $311.4(80.1)$ & $337.8(82.3)$ & $326.5(82.3)$ & 0.006 & 0.068 & 0.017 \\
\hline MPA (min/day) & $41.2(27.3)$ & $35.2(21.0)$ & $37.8(24.0)$ & 0.039 & $38.9(22.7)$ & $41.5(24.4)$ & $40.4(23.7)$ & 0.362 & 0.188 & 0.040 \\
\hline VPA (min/day) & $4.6(8.2)$ & $5.4(9.5)$ & $5.1(9.0)$ & 0.404 & $2.7(5.7)$ & $2.1(4.3)$ & $2.3(4.9)$ & 0.265 & $<0.001$ & 0.176 \\
\hline MVPA (min/day) & $45.8(30.0)$ & $40.7(25.1)$ & $42.9(27.4)$ & 0.119 & $41.7(25.0)$ & $43.5(25.9)$ & $42.7(25.5)$ & 0.534 & 0.947 & 0.141 \\
\hline PA weekdays (cpm) & $415.2(162.8)$ & 390.6 & $401.2(153.9)$ & 0.170 & $365.7(146.0)$ & $396.0(149.9)$ & $383.0(148.7)$ & 0.082 & 0.142 & 0.032 \\
\hline PA weekends (cpm) & $448.5(249.1)$ & $435.7(205.6)$ & $441.2(225.1)$ & 0.629 & $431.8(211.8)$ & $421.7(198.9)$ & $426.0(204.2)$ & 0.674 & 0.391 & 0.941 \\
\hline
\end{tabular}

PA, physical activity; MPA, moderate physical activity; VPA, vigorous physical activity; MVPA, moderate-to-vigorous physical activity; $\mathrm{cpm}$, counts per minute 

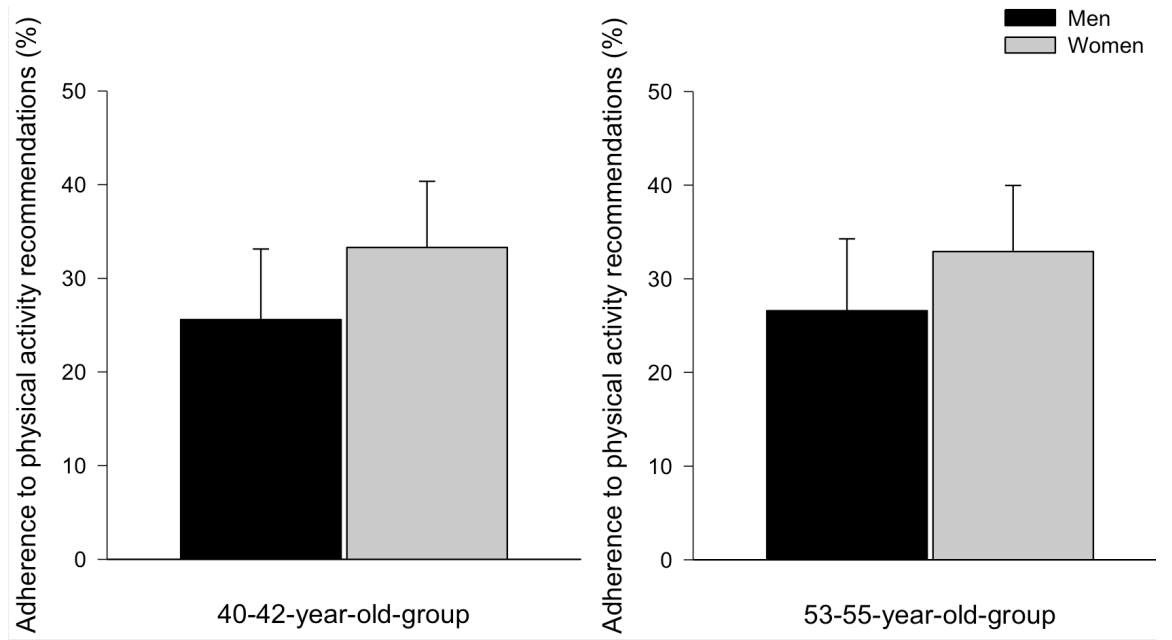

Figur 2. Adherence (\%) to physical activity recommendations (phase 1) by age and sex. For

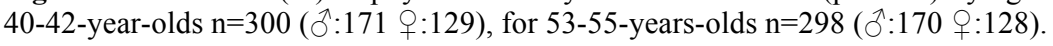
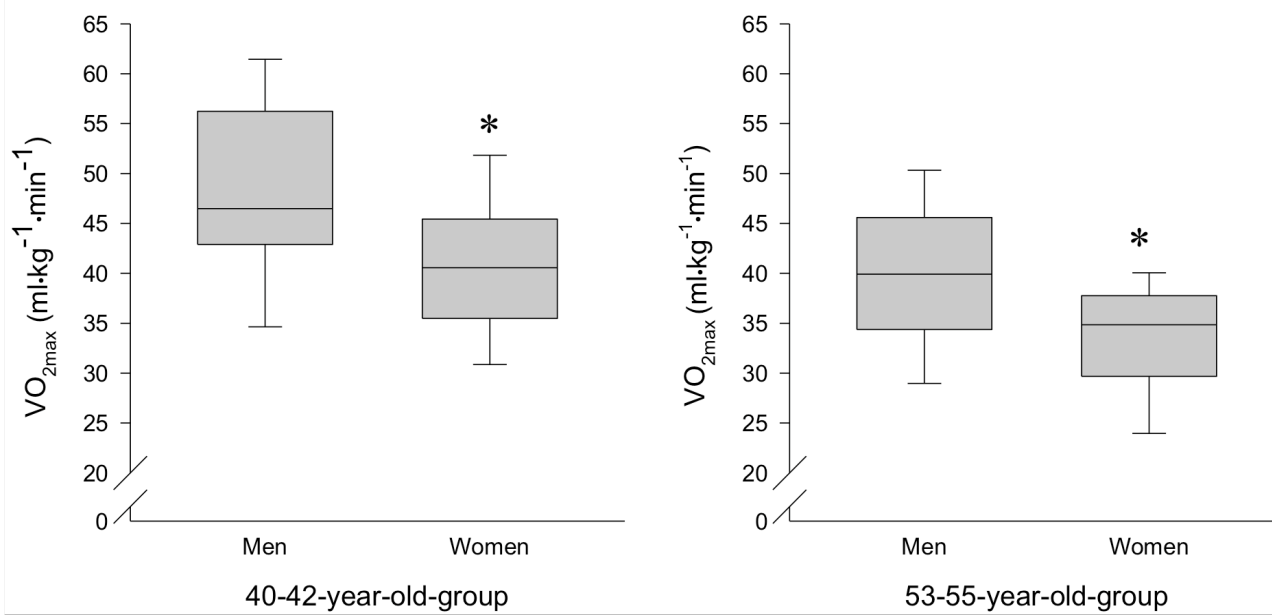

Figure 3. Box plot of cardiorespiratory fitness $\left(\mathrm{ml} \cdot \mathrm{kg}^{-1} \cdot \mathrm{min}^{-1}\right)$ by age and sex. For $40-42$-year-olds $\mathrm{n}=82$ $\left(\delta^{\wedge}: 35\right.$ + $\left.: 47\right)$, for 53-55-years-olds $n=99\left(0^{1}: 37\right.$ o $\left.: 62\right)$. The box covers the range between the lower and the upper quartiles; the whiskers cover the range between the $5^{\text {th }}$ and the $95^{\text {th }}$ percentiles, and the horizontal bar dividing the box indicates the mean. ${ }^{*} p<0.001$ between sexes in both age-groups and between age-groups.

between age-groups and sex, significant findings were made regarding inactivity $(\mathrm{p}=0.014)$, light activity $(\mathrm{p}=0.017)$, MPA $(\mathrm{p}=0.040)$ and PA during weekdays $(\mathrm{p}=0.032)$. Women had $35.6 \mathrm{cpm}$ [95\% CI: 16.1 to $55.0]$ and men had $48.9 \mathrm{cpm}$ [95\% CI: 23.3 to 75.0$]$ higher overall PA levels during weekends than on weekdays.

Figure 2 shows adherence to the PA recommendation. In the 40-42-year-old-group 30.0\% [95\% CI: 24.8 to 35.2$]$ met the recommendations, while $30.2 \%$ [ $95 \%$ CI: 25.0 to 35.4$]$ met the recommendations in the 5355-year-old-group. There were no significant differences between the sexes or age-groups.

Figure 3 displays CRF by age-group, in total and by sex. In the 40-42-year-old-group, women had 7.4 $\mathrm{ml} \cdot \mathrm{kg}^{-1} \cdot \mathrm{min}^{-1}$ [95\% CI: -11.0 to -3.8$]$ lower $\mathrm{VO}_{2}$ max compared to men, whereas women in the 53-55-yearold-group had $7.3 \mathrm{ml} \cdot \mathrm{kg}^{-1} \cdot \mathrm{min}^{-1}$ [95\% CI: -10.4 to-4.1] lower $\mathrm{VO}_{2 \text { max }}$ compared to men. Furthermore, the 4042-year-old-group had $8.2 \mathrm{ml} \cdot \mathrm{kg}^{-1} \cdot \mathrm{min}^{-1}$ [95\% CI: 5.6 to 10.7] higher $\mathrm{VO}_{2}$ max compared to the 53-55-yearold-group.

There was a medium, positive correlation between overall PA level (cpm) and CRF $\left(\mathrm{ml} \cdot \mathrm{kg}^{-1} \cdot \mathrm{min}^{-1}\right)$ in both sexes. For men $\mathrm{r}=0.40$ [95\% CI: 0.18 to 0.58$]$ and for women $\mathrm{r}=0.42$ [95\% CI: 0.25 to 0.56$]$, with high overall PA level associated with high CRF.

\section{Discussion}

\section{Physical activity}

The present study shows higher overall PA level and adherence to the PA recommendations compared to the national sample in Kan1 (13). Furthermore, when comparing our data to international studies such as the National Health and Nutrition Examination Survey 
(NHANES) and the Attitude Behaviour and Change Study (ABC-study), the same conclusions can be drawn (25). However, it is difficult to compare these studies due to the difference in cut-off points for agegroups in all four studies, and slightly different methods of data reduction and definitions of PA recommendations in the NHANES and ABC-study compared to Kan1 and the present study. Adherence to PA recommendations in the present study is in contrast to previous studies which used self-reporting and found higher adherence to the recommendation $(13,17)$. On the other hand, Haakstad and Bø (15) found markedly lower degrees of adherence to PA recommendations using self-report. Discrepancies between studies are most likely due to differences in the questions and the limitations of self-report as mentioned earlier. Although there is a higher adherence to the PA recommendations in Sogn og Fjordane compared to the national sample, from a public health perspective, $30 \%$ is not satisfactory taken into account the convincing evidence of health outcomes for those who meet the PA recommendations (9). This emphasizes the importance of implementing effective strategies to increase the daily PA level.

The higher overall PA level on weekends compared to weekdays found is consistent with the findings in Kan1 (13). However, the difference reported in Kan1 is minimal compared to the present study. The present study shows higher PA levels on both weekdays and weekends compared to Kan1, but the difference is more marked during weekends $(\mathrm{p}=0.013)$. This indicates that 40-42-year-olds and 53-55-year-olds in Sogn og Fjordane are especially active during weekends compared to the national sample. This might be due to easy access to outdoor-life, which is supported by the fact that $88 \%$ reported walking and hiking, a typical Norwegian weekend activity, as activities done on a regular basis (data not shown), compared to $79 \%$ in the national sample in Kan1 (13).

The present study shows no sex difference in overall PA. This is in line with Kan1 (13), but in contrast with NHANES and the ABC-study, where men were found to be more physically active than women (22, 23). However, sex differences in different intensities of PA were found in the present study, indicating that in the 40-42-year-old-group men spent more time in MPA than women, and that in the 53-55-year-old group men spent more time on inactivity and less time in light activity than women. These results are in agreement with those reported in the Kan1 study (13) and partly in line with the results of the NHANES and ABC-study (25). In contrast to Kan 1, results in the present study revealed age-group differences showing more time spent in VPA among 40-42-year-olds compared to the 53-55-year-olds.

\section{Cardiorespiratory fitness}

Few comparable studies investigating CRF in a representative population exist. Findings from the present study show higher CRF for both sexes and age-groups compared to the national sample in Kan1 (29). Furthermore, the same conclusion was reached when compared to a study by Haakstad and Bø (15), however, this study used an indirect measure of CRF. In both age-groups in the present study, men had higher CRF than women. This is in agreement with the existing literature, claiming a $15-30 \%$ lower $\mathrm{VO}_{2 \max }$ for women compared to men (33). As expected, the 40-42year-old-group has higher CRF compared to the 5355 -year-old-group. This finding is consistent with the yearly age-related $1 \%$ decline in $\mathrm{VO}_{2 \max }$ for adults described in the literature (33), indirectly validating data representativeness.

As expected, positive correlations between PA and $\mathrm{CRF}$ in both sexes were found. These findings are supported by Løchen et al. (14), who found a correlation coefficient of 0.18 in men and 0.39 in women. The stronger correlation in the present study might be due to more accurate measurements, as PA is measured objectively and CRF is measured directly. Løchen et al. (14) explained the sex difference by the fact that the fitness test truly was maximal in most women while the load was too low for many men. The fact that direct measurement of CRF was used in the present study might explain the small difference in correlation with sex.

\section{Cardiovascular disease risk factors}

BMI is marginally lower compared to the national sample in Kan1 (13) and marginally higher for the 4042-year-old-group compared to previous collected BMI data from the population in Sogn og Fjordane (34). For women, BMI is lower compared to data from the HUNT study (35) and the Tromsø study (36). For men, the BMI results are in line with the HUNT data in both age-groups and slightly higher compared to the Troms $\varnothing$ data for the 53-55-year-olds. BMI is not a direct measurement of body fatness and does not distinguish between fat and muscle mass, but is a surrogate for adiposity and an applicable measure to use in population based studies (37).

For the 40-42-year-olds, SBP is marginally lower, especially for women, compared to results from the National Health Screening Service in Sogn og Fjordane in the mid-nineties, while DBP is higher in the present study in both sexes (38). When comparing blood pressure with previous studies one should bear in mind that different measuring devices for blood pressure have been used. The present study used an automatic Omron HEM-907 BP monitor, while the National Health Screening Services used an automatic Dinamap (39).

In the present study, both sexes in the 40-42-yearold-group have lower prevalence of daily smokers, lower TC and higher HDL-c compared to the National Health Screening Services in Sogn og Fjordane in 1996 (38). These findings are consistent with the findings of Jenum et al. (40), which show a decrease in TC 
and smoking habits through thirty years. There is no difference in the prevalence of daily smokers in the present study compared to Kan1. However, the percentages of 'have never smoked' is higher and 'smoked earlier' is lower in the present study compared to Kan1 (13).

Sogn og Fjordane County has Norway's longest living population (26). The county has a reputation of being the most healthy county in Norway (27) and is among the counties with lowest CVD mortality (28). Furthermore, the observation of the population of Sogn og Fjordane being more PA and having higher CRF underscores this statement.

\section{Strength and limitations}

Objectively measured PA, high compliance with the protocol and directly measured CRF strengthen the findings reported in this study. Also, the high response rate from a narrow age sample is a strength. However, these findings should be interpreted in light of the following limitations. First, this cross-sectional study does not allow explanations of causality. Second, the accelerometer is not able to accurately assess nonambulatory activity, such as cycling or swimming (41). For people who cycle or do upper-body exercises on a regular basis, PA is underestimated. However, Kan1 shows that people mostly do ambulatory activities (13). Third, the uniaxial Actigraph used in the present study does not register high-speed activity satisfactory, such as running over $10 \mathrm{~km} / \mathrm{h}$. However, the large majority of people carry out little regular running at this speed (41). Fourth, the PA intensity thresholds vary widely between studies (41). This hampers study comparability and underlines the uncertainty of the cut-off points. The present study uses the same cut-off points as were used in Kan1 and NHANES $(13,23)$. Fifth, non-fasting blood samples were taken in phase
2, which gives higher values of glucose and triglycerides than if they had been taken in the fasting state. However, this was done to facilitate comparison with previous studies using non-fasting blood samples (39). Sixth, although the response rate was high compared to recent similar studies, almost $40 \%$ chose not to participate, and we cannot rule out the possibility of a selection bias. Because the aim of the study was to assess levels of PA and CRF, it is likely that the most physically active participated. If this is correct, there are reasons to believe that several of our findings may be overestimated.

\section{Conclusions}

The aim of this cross-sectional study was to describe levels of objectively measured PA, directly measured CRF and CVD risk factors in an adult population in the county of Sogn og Fjordane. These results support the hypotheses that the population of Sogn og Fjordane County are more physically active and have higher CRF compared to the rest of the Norwegian population. However, from a public health perspective, taken into account the convincing evidence of health outcomes for those who meet the PA recommendations, $30 \%$ adherence to the PA recommendations is not satisfactory. Therefore, it is necessary to implement effective strategies aiming to increase daily PA level.

\section{ACKNOWLEDGEMENTS}

Financial support for this study was received from the Sogn og Fjordane County Council and the Sparebanken Vest - Visjon Vest. The authors are grateful to the 622 people who gave their time to the study. We also thank Tone Merete Hagen and Sigrid Henjum for blood sampling, Petter Urdal at the Department of Medical Biochemistry, Oslo University Hospital, Ullevaal for blood analyses and Bjørge Herman Hansen concerning the help with the ActiGraph data reduction.

\section{REFERENCES}

1. Blair SN, Cheng Y, Holder JS. Is physical activity or physical fitness more important in defining health benefits? Med Sci Sports Exerc 2001; 33 (6 Suppl): 379-99.

2. Aadahl M, Kjær M, Jørgensen T. Associations between overall physical activity level and cardiovascular risk factors in an adult population. Eur J Epidemiol 2007; 22 (6): 369-78.

3. Ekblom-Bak E, Hellenius ML, Ekblom O, et al. Independent associations of physical activity and cardiovascular fitness with cardiovascular risk in adults. Eur J Cardiovasc Prev Rehabil 2010; 17 (2): 175-80.

4. World Health Organization. Global health risks. Mortality and burden of disease attributable to selected major risks. 2009. Genova. World Health Organization.

5. Blair SN, Kampert JB, Kohl HW, III, et al. Influences of cardiorespiratory fitness and other precursors on cardiovascular disease and all-cause mortality in men and women. JAMA 1996; 276 (3): 205-10.

6. Haskell WL, Lee IM, Pate RR, et al. Physical activity and public health. Updated recommendation for adults from the American College of Sports Medicine and the American Heart Association. Circulation $2007 ; 116$ (9): 1081-93.

7. Becker W, Alexander J, Andersen S, et al. [Nordic nutrition recommendations]. Ugeskr Laeger 2006; 168 (1): 76-7.

8. Sosial- og Helsedirektoratet. Fysisk aktivitet og helse. Anbefalinger [Physical Activity and Health. Recommendations]. Rapport 2. 2000. Oslo. Sosial- og helsedirektoratet. 
9. Leitzmann MF, Park Y, Blair A, et al. Physical activity recommendations and decreased risk of mortality. Arch Intern Med 2007; 167 (22): 2453-60.

10. Warren JM, Ekelund U, Besson H, et al. Assessment of physical activity - a review of methodologies with reference to epidemiological research: a report of the exercise physiology section of the European Association of Cardiovascular Prevention and Rehabilitation. Eur J Cardiovasc Prev Rehabil 2010; 17 (2): 127-39.

11. Aires N, Selmer R, Thelle D. The validity of self-reported leisure time physical activity, and its relationship to serum cholesterol, blood pressure and body mass index. A population based study of 332,182 men and women aged 40-42 years. Eur J Epidemiol 2003; 18 (6): 479-85.

12. Sallis JF, Saelens BE. Assessment of physical activity by self-report: status, limitations, and future directions. Res $Q$ Exerc Sport 2000; 71 (2 Suppl): 1-14.

13. Helsedirektoratet. Fysisk aktivitet blant voksne og eldre i Norge - Resultater fra en kartlegging i 2008 og 2009 [Physical Activity among Adults and Elderly in Norway]. IS-1754. 2009. Oslo. Helsedirektoratet.

14. Løchen ML, Rasmussen K. The Tromsø study: physical fitness, self reported physical activity, and their relationship to other coronary risk factors. J Epidemiol Community Health 1992; 46 (2): 103-7.

15. Haakstad LAH, Bø K. Fitness and physical activity in Norwegian adults. Adv Physiother 2007; 9: 89-96.

16. Graff-Iversen S, Skurtveit S, Nybø A, et al. [Trends when it comes to occupational physical activity among Norwegians aged 40-42 years during the period 1974-94]. Tidsskr Nor Laegeforen 2001; 121 (22): 2584-8.

17. Anderssen SA, Andersen LB. Fysisk aktivitetsnivå i Norge 2003: Data basert på spørreskjemaet "International Physical Activity Questionnaire" [Level of Physical Activity in Norway 2003]. IS-1254. 2004. Oslo. Sosialog Helsedirektoratet.

18. Søgaard AJ, Bø K, Klungland M, et al. En oversikt over norske studier - hvor mye beveger vi oss i fritiden? [A review of Norwegian studies - how much do we exercise during our leisure time?]. Tidsskr Nor Lageforen 2000; 120 (28): 3439-46.

19. Helsedirektoratet. Omnibus. 2008.

20. Shephard RJ. Limits to the measurement of habitual physical activity by questionnaires. Br J Sports Med 2003; 37 (3): 197-206.

21. Freedson PS, Miller K. Objective monitoring of physical activity using motion sensors and heart rate. Res $Q$ Exerc Sport 2000; 71 (2 Suppl): 21-9.

22. Hagströmer M, Oja P, Sjöström M. Physical activity and inactivity in an adult population assessed by accelerometry. Med Sci Sports Exerc 2007; 39 (9): 1502-8.

23. Troiano RP, Berrigan D, Dodd KW, et al. Physical activity in the United States measured by accelerometer. Med Sci Sports Exerc 2008; 40 (1): 181-8.

24. Bauman A, Bull F, Chey T, et al. The International Prevalence Study on Physical Activity: results from 20 countries. Int J Behav Nutr Phys Act 2009; 6 (1): 21.

25. Hagströmer M, Troiano RP, Sjöström M, et al. Levels and patterns of objectively assessed physical activity a comparison between Sweden and the United States. Am J Epidemiol 2010; 171 (10): 1055-64.

26. Norgeshelsa. Forventet levealder [Life expentancy]. http://www.norgeshelsa.no/norgeshelsa. Downloaded: 16-9-2010.

27. Bjartveit K, Wøien G. Cardiovascular disease risk factors in Norway - Results from surveys in 18 counties. 1997. Oslo. National Health Screening Service.

28. Norgeshelsa. Dødsårsak [Cause of death]. http://norgeshelsa.no/norgeshelsa. Downloaded: 16-9-2010.

29. Helsedirektoratet. Fysisk form blant voksne og eldre i Norge - Resultater fra en kartlegging i 2009-2010 [Physical Fitness among Adults and Elderly in Norway]. IS-1816. 2010. Oslo. Helsedirektoratet.

30. Friedewald WT, Levy RI, Fredrickson DS. Estimation of the concentration of low-density lipoprotein cholesterol in plasma, without use of the preparative ultracentrifuge. Clin Chem 1972; 18 (6): 499-502.

31. Balke B. [Optimum physical working capacity, its measurement and change as a result of the working fatigue.]. Arbeitsphysiologie 1954; 15 (4): 311-23.

32. Holme I, Waaler HT. Five-year mortality in the city of Bergen, Norway, according to age, sex and blood pressure. Acta Med Scand 1976; 200 (3): 229-39.

33. McArdle WD, Katch FI, Katch VL. Exercise Physiology. Baltimore: Lippincott Williams \& Wilkins, 2001.

34. Tverdal A. [Height, weight and body mass index of men and women aged 40-42 years]. Tidsskr Nor Laegeforen 1996; 116 (18): 2152-6.

35. Drøyvold WB, Nilsen TI, Krüger $\varnothing$, et al. Change in height, weight and body mass index: Longitudinal data from the HUNT Study in Norway. Int J Obes 2006; 30 (6): 935-9.

36. Wilsgaard T, Arnesen E. Body mass index and coronary heart disease risk score: the Tromsø study, 1979 to 2001. Ann Epidemiol 2007; 17 (2): 100-5.

37. World Health Organization. Physical Status: The use and interpretation of anthropometry. Technical Report Series No. 854. 1995. Geneva, Switzerland. 
38. Wøien G, Øyen O, Graff-Iversen S. 22 years of cardiovascular surveys in Norwegian counties. Is the development in risk factors satisfactory? Nor J Epidemiol 1997; 7 (2): 255-66.

39. Bjartveit K, Stensvold I, Lund-Larsen PG, et al. [Cardiovascular screenings in Norwegian counties. Background and implementation. Status of risk pattern during the period 1986-90 among persons aged 40-42 years in 14 counties]. Tidsskr Nor Laegeforen 1991; 111 (17): 2063-72.

40. Jenum AK, Graff-Iversen S, Selmer R, et al. [Risk factors for cardiovascular disease and diabetes through three decades]. Tidsskr Nor Laegeforen 2007; 127 (19): 2532-6.

41. Corder K, Brage S, Ekelund U. Accelerometers and pedometers: methodology and clinical application. Curr Opin Clin Nutr Metab Care 2007; 10 (5): 597-603. 